\title{
Sudden Cardiac Death in the Young: A Strategy for Prevention by Targeted Evaluation
}

\author{
Srijita Sen-Chowdhry ${ }^{a, b}$ William J. McKenna ${ }^{a}$ \\ ${ }^{\text {a }}$ Centre for Cardiology in the Young, The Heart Hospital, University College London, and \\ ${ }^{b}$ National Heart and Lung Institute, Imperial College, London, UK
}

Winner of the H.J.C. Swan Memorial Prize for Medical Writing

\section{Key Words}

Arrhythmia $\cdot$ Cardiomyopathy $\cdot$ Genetics $\cdot$ Sudden death

\begin{abstract}
The annual incidence of sudden cardiac death (SCD) in the general population is estimated as 1 in a 1,000. Since survival rates from out-of-hospital cardiac arrests are poor, primary prevention is key to reducing the burden of SCD in the community. Prominent causes of SCD include ischaemic heart disease, anomalous coronary arteries, and the primary myocardial diseases: hypertrophic cardiomyopathy, dilated cardiomyopathy, and arrhythmogenic right ventricular cardiomyopathy (ARVC). In $4 \%$ of sudden deaths in the 16-64 age group, postmortem examination fails to identify a cause, yielding a default diagnosis of sudden arrhythmic death syndrome (SADS). The inherited arrhythmia syndromes (long OT, short QT, and Brugada syndromes, and familial catecholaminergic polymorphic ventricular tachycardia) may be implicated in SADS, owing to their propensity for pro-
\end{abstract}

ducing ventricular tachyarrhythmia in the structurally normal heart. Monogenic disorders therefore predominate as causes of SCD in the young. The advent of effective therapies for these diseases, particularly implantable cardioverter defibrillators, has prompted calls for universal screening to enable timely diagnosis of occult cardiac disease. Since prospective cardiac assessment of the general population is not feasible, the solution may be to target high-risk subgroups, namely, patients with cardiac symptoms, relatives of SCD victims, and competitive athletes. The recommended preliminary work-up includes a 12-lead ECG, signal-averaged ECG, transthoracic echocardiogram, exercise test, and ambulatory ECG monitoring. Cardiovascular magnetic resonance is a useful adjunct in patients with suspected ARVC or anomalous coronary arteries. Provocative challenge with a sodium challenge blocker may be of value in unmasking the Brugada syndrome. Identification of disease-causing mutations in affected individuals facilitates cascade screening of families.

Copyright (C) 2006 S. Karger AG, Basel

Dr. Srijita Sen-Chowdhry

c/o Prof. William J. McKenna, Centre for Cardiology in the Young, The Heart Hospital

16-18 Westmoreland Street, London W1G 8PH (UK)

Tel. +44 207573 8841, Fax +44 2075738838

E-Mailsrijita@aol.com,william.mckenna@uclh.org
KARGER
Fax +4161306 1234

E-Mail karger@karger.ch

www.karger.com

\section{8-6312/06/1054-0196\$23.50/0}

Accessible online at:

www.karger.com/crd 


\section{Population-Based Strategies}

In the past, publicity related to SCD frequently focused on athletes [9], providing impetus for the development of pre-participation screening programmes. More recently, growing awareness that SCD in young people is not confined to the sporting arena has prompted calls for universal prospective cardiac assessment. The obstacles to such an initiative are manifold. First, clinical findings in many arrhythmic disorders are subtle and non-specific. Arrhythmogenic right ventricular cardiomyopathy (ARVC), for example, is well known to demonstrate a 'concealed' phase during which a cardiac work-up may be unremarkable $[10,11]$. Similarly, almost a third of gene carriers in long QT syndrome have a corrected QT interval within normal limits [12]. In spite of the lack of discernible features on clinical assessment, these subgroups may be at risk of arrhythmic events.

The components of the cardiac evaluation also warrant discussion. Recommended screening for high school and college athletes in the USA comprises a full history and physical examination, which have limited efficacy in detecting occult cardiovascular disease. In contrast, preparticipation screening in Italy includes two additional components: a 12-lead electrocardiogram (ECG) and limited step exercise test [13].

Corrado et al. [13] prospectively studied sudden deaths among the $\leq 35$ age group in the Veneto region of Italy from 1979 to 1996 . HCM was detected in 22 of almost 34,000 athletes assessed, with ECG abnormalities instigating further investigations in $73 \%$. While HCM is the leading cause of SCD in young athletes worldwide, accounting for around one third of cases, it was rare (2\%) among competitive athletes who died suddenly in the Italian series. Conversely, the incidence of HCM among SCD victims who were not athletes was comparable to other surveys. The primary causes of SCD among Italian athletes were ARVC, atherosclerotic coronary artery disease, and anomalous coronary arteries. These findings suggest that a cardiac work-up including a 12-lead ECG may be of value in identifying HCM, but appears relatively ineffective for early diagnosis of ARVC and coronary artery disease [13]. Neither does a normal baseline ECG exclude the inherited arrhythmia syndromes. Inclusion of twodimensional echocardiography, maximal exercise testing, and ambulatory ECG monitoring in the cardiac assessment would improve its sensitivity but diminish cost-effectiveness in the general population. The added need for expert cardiac interpretation of each investigation would place an untenable drain on resources.
A further issue arising in any putative universal screening programme is the timing of assessment. Standardised examination of school-leavers has been proposed. Contrary to prevalent perceptions, however, the cardiac diseases implicated in SCD may present at any age. A normal evaluation at any particular time of life therefore has a relatively low negative predictive value for future arrhythmic events, limiting reassurance for the individual. The heart muscle diseases, for example, show age-related penetrance. Recognition of late-onset HCM, often in association with mutations in myosin binding protein $\mathrm{C}$, has refuted the traditional view that the disease becomes manifest in all genetically affected individuals by early adulthood $[14,15]$. The current guidelines for familial HCM therefore advise continued assessments on a 5yearly basis for relatives who have normal ECG and echocardiogram at the age of 18 [15]. Similar evidence-based recommendations exist for familial dilated cardiomyopathy (DCM) [16]. Periodic and comprehensive re-assessment is encouraged in ARVC owing to the possibility of a prolonged concealed phase; new clinical features may develop from early puberty to middle age and beyond [11]. Evolution of characteristic ECG abnormalities over a 7-year interval has been documented [17].

False negatives aside, Bayes' theorem dictates that the positive predictive value of a screening test is dependent on the prevalence of the disease state in the population under examination. Thus, screening the general population will inevitably lead to a significant proportion of false positives, with healthy subjects undergoing extensive evaluation and suffering undue psychological distress. Numerous drawbacks therefore preclude universal cardiac screening for the prevention of SCD.

\section{Targeted Evaluation: A Feasible Alternative?}

Selective cardiac evaluation of high-risk subgroups may offer a viable solution. Individuals with cardiac symptoms are the first group worth targeting. Retrospective studies have suggested that premonitory symptoms occur in a significant proportion of patients with ARVC, long QT syndrome, and anomalous coronary arteries [6, 18-20].

Besides coronary artery disease, which shows multifactorial inheritance, monogenic disorders prevail as causes of SCD in the young. The majority are commonly transmitted as autosomal dominant traits with incomplete penetrance, although recessive and X-linked inheritance are also recognised in certain conditions (table 1). 
Thus, the families of SCD victims represent the second group requiring cardiac evaluation. Pre-participation screening of athletes engaging in competitive sports and/ or high-level endurance training should also be encouraged.

Integral to the strategy of targeted evaluation is the need to promote public awareness of cardiac symptoms and encourage primary care physicians to seek a cardiology opinion. The clinical diagnosis of ARVC and the inherited arrhythmia syndromes is challenging and best conducted at specialist centres with extensive experience in the field.

\section{The Young Patient with Cardiac Symptoms}

\section{Importance of the Family History}

In a young patient with cardiac symptoms, a history of premature SCD in a relative serves as an immediate 'red flag' for the clinician. Its absence does not, however, obviate the need for further investigations. Sporadic and multifactorial disorders that warrant exclusion in this population include atherosclerotic and congenital anomalous coronary artery disease, and valvular abnormalities. Furthermore, a benign family history does not preclude monogenic diseases owing to incomplete penetrance of autosomal dominant traits and, less commonly, recessive inheritance or de novo mutations.

\section{Chest Pain and Dyspnoea}

Chest pain and mild breathlessness on exertion are common complaints in the young, the significance of which is often difficult to determine. While classic angina is readily discernible from the history, atypical chest pain is far more frequent in this population. The majority of cases are likely to be musculoskeletal. Nevertheless, chest pain also occurs in conjunction with HCM, where it is usually attributable to left ventricular outflow tract obstruction and/or ischaemia from small vessel disease and capillary-mass mismatch. Chest pain in DCM has also been ascribed to microvascular dysfunction [21], and in ARVC it may be related to intimal and medial hyperplasia of the coronary arteries [22]. Both angina and atypical chest pain may occur as a prodrome in patients with anomalous coronary arteries. A fallible but practical rule of thumb may be to investigate atypical chest pain when severe, recurrent, and/or exertional.

Acute self-limited difficulty in breathing raises a suspicion of arrhythmic episodes, while significant chronic dyspnoea may be a manifestation of systolic impairment in DCM, or diastolic dysfunction and/or left ventricular outflow tract obstruction in HCM. Exercise testing with metabolic gas exchange measurements offers a means of objectively assessing functional capacity in young patients with breathlessness.

\section{Palpitation}

A history of sustained palpitation always warrants further investigation. Associated symptoms such as difficulty in breathing and/or impairment in consciousness raise suspicion of a ventricular tachyarrhythmia and intensify the need for urgent assessment. Conversely, dyspnoea and pre-syncope may occur in patients with supraventricular arrhythmia, while ventricular tachycardia in some patients with cardiomyopathy may be surprisingly well tolerated. The routine work-up recommended below is designed to detect underlying diseases that may predispose to SCD, but may not identify common causes of palpitation such as atrioventricular (AV) nodal re-entrant tachycardia. Thus, in the presence of a normal cardiac evaluation, the mainstay of the approach to a patient with palpitation is to capture the rhythm with ambulatory ECG monitoring. Diagnosis is dependent on the recording coinciding with the patient's perception of palpitation. Documentation of benign arrhythmia in the absence of symptoms does not suffice; a patient with asymptomatic runs of supraventricular tachycardia may well be experiencing palpitation secondary to ventricular tachyarrhythmia on other occasions. Neither does a negative electrophysiological study obviate the need to document spontaneous arrhythmia. A cardiac memo or loop recorder is indicated if episodes occur relatively infrequently.

Syncope

Syncope is defined as sudden loss of consciousness and postural tone with spontaneous recovery. It has been suggested that syncope of cardiac origin is the same thing as sudden death, except that you wake up [23]. While the majority of syncopal episodes in adolescents and young adults are neurally mediated, an approach based on this premise may not be amiss if obvious extraneous factors are lacking. Prolonged standing, abrupt postural changes, and volume depletion are recognised precipitants of vasovagal syncope. Conversely, syncope warrants emergent evaluation when exertional, recurrent, associated with other cardiac symptoms, leading to injury, or complicated by seizure activity.

In the presence of a normal cardiac evaluation, capturing the event once again becomes paramount. Tilt testing is of limited value in patients with unexplained syncope 
as a positive test does not exclude a primary arrhythmic cause. Long-term monitoring, with an implantable loop recorder if necessary, is more likely to elicit a diagnosis [24-26].

The clinical significance of syncope in patients with underlying cardiac disease depends on its nature. In a patient with DCM, ARVC, or one of the inherited arrhythmia syndromes, unexplained syncope is presumed secondary to ventricular tachyarrhythmia until proven otherwise. In the HCM patient, disease-related syncope may occur secondary to supraventricular arrhythmia, left ventricular outflow tract obstruction, vascular instability, or ventricular arrhythmia. Collapse in a young person with anomalous coronary arteries has a distinct mechanism. The most malignant anomalies are those in which either the right or left main coronary artery originates from the wrong aortic sinus and subsequently courses between the aorta and the pulmonary artery. Augmented cardiac output during exercise results in dilation of the great vessels, which impinge on the proximal segment of the anomalous artery, resulting in reduced flow at a time of increased demand. Spasm of the anomalous segment may also be contributory. In the absence of collateral flow, the haemodynamic impact may be likened to that of acute left main stem occlusion, with consequent collapse and/or ventricular fibrillation. Coronary anomalies are amenable to surgical correction, underscoring the importance of timely recognition.

\section{Pre-Syncope}

True pre-syncope is the sensation of impending loss of consciousness, manifested by the following complex of symptoms: severe light-headedness, weakness, transient darkening of vision, hearing loss, and/or difficulty maintaining postural tone. As such, pre-syncope is comparable in aetiology to syncope and warrants a similar approach. Mild dizzy spells, in contrast, are non-specific and their clinical significance difficult to define.

Normal subjects commonly experience light-headedness in association with postural changes, or when coming to a 'sudden stop' after exercise. Sympathetic stimulation, muscle activity, and decreased intrathoracic pressure all contribute to increased venous return during physical exertion. Abrupt cessation of muscular contraction after exercise may result in diminished central blood volume, hypotension, and a light-headed sensation. Thus, lightheadedness and a blood pressure drop in the recovery period may be physiological, while pre-syncope during exercise justifies concern.

\section{The Family with a History of SCD}

\section{Importance of the Post-Mortem}

When performing a post-mortem on a sudden death victim, the expert pathologist will systematically attempt to exclude all structural cardiac abnormalities, including coronary artery disease, accessory pathways, conduction system defects, valve lesions, HCM, DCM, left ventricular non-compaction, and ARVC. This process entails rigorous macroscopic and histological assessment of the heart. The arrhythmogenic cardiomyopathies, in particular, are easily missed on autopsy without extensive sampling of both ventricles. ARVC may be the underlying pathology in a proportion of deaths ascribed to acute myocarditis; inflammatory infiltrates are a feature of up to $67 \%$ of ARVC hearts, and in early disease may predominate over the characteristic fibrofatty replacement [27-29].

Obtaining a complete post-mortem report from the index case is the first step to conducting clinical assessment of the family. If the cardiac examination appears incomplete and details are lacking, the clinician may seek the consent of the family to release retained tissue for expert review. Re-assessment by a specialist cardiac pathologist may unmask new abnormalities in cases where the cause of death was unascertained, and/or consolidate a borderline diagnosis. Confirmation of a sporadic disorder, such as anomalous coronary arteries, may obviate the need for familial evaluation. The presence of premature coronary artery disease may prompt familial screening for hyperlipidaemias, plasma homocysteine and lipoprotein (a) levels [30-33]. Identification of an inherited cardiomyopathy facilitates subsequent evaluation of relatives along disease-specific guidelines $[11,15,16]$.

\section{Approach to the SADS Family}

A 'negative' post-mortem yields a default diagnosis of SADS. Caused by mutations in ion channels and ion regulatory proteins, the inherited arrhythmia syndromes (table 1) have long been speculated to underlie SADS owing to their propensity for producing arrhythmia in the structurally normal heart. Behr et al. [6] systematically assessed the families of 32 SADS victims and found evidence of inherited cardiovascular disease in 7 (22\%). As hypothesised, long QT syndrome was the most prevalent diagnosis among relatives with cardiac abnormalities. Of particular note, however, was the detection of HCM in one family and myotonic dystrophy in another, since both diseases are associated with abnormal histopathology. Unexplained left ventricular hypertrophy, myocyte disar- 
ray, and fibrosis are the characteristic features of HCM, while the heart in myotonic dystrophy shows fibrofatty infiltration and atrophy of the conduction system and/or ventricles [34, 35]. Structural heart disease therefore remains part of the differential diagnosis in SADS families, in spite of the lack of post-mortem findings in the index case. Recent data further indicate that a significant proportion of SADS families show features consistent with ARVC [Sen-Chowdhry and McKenna, unpubl. data]. The work-up for relatives of SADS victims should therefore aim to identify both primary myocardial diseases and inherited arrhythmia syndromes.

Questioning families regarding premonitory symptoms in the proband and the circumstances of death may provide clues to the underlying diagnosis. Long QT syndrome, for example, has several clinical subtypes caused by distinct ion channel mutations. The triggers for arrhythmic events appear to be gene specific. Thus, exercise-induced events predominate in the LQT1 subtype; swimming and diving, in particular, are recognised precipitants. In contrast, both LQT3 and Brugada syndrome are associated with arrhythmic events during sleep, while LQT2 shows an intermediate pattern. Auditory stimuli and emotional stress are particularly common triggers in LQT2. It should be emphasised, however, that these observations represent general trends rather than absolutes; thus, 3\% of LQT1 patients experienced events while asleep, while $13 \%$ of LQT3 patients had arrhythmia during exercise [36]. Similarly, although intense physical exertion may induce arrhythmia in HCM and ARVC, the majority of events in both diseases occur at rest or during everyday life activities [37, 38].

\section{Recommended Baseline Work-Up}

The evaluation outlined in this section is designed to identify significant occult cardiac disease in a young, symptomatic patient or a family with a history of SCD. This preliminary work-up is more extensive than that advised for familial assessment in HCM or DCM, where a 12-lead ECG and 2D echocardiogram will suffice as screening investigations. The recommendations below presume that there is no known cardiac history in the family, precluding the use of disease-specific guidelines.

\section{History and Pedigree}

All patients should be questioned specifically about the presence of cardiac symptoms, as described above. Compilation of a detailed family history, covering a min- imum of three generations, is also mandatory. Simply inquiring about sudden deaths is seldom instructive; construction of a pedigree stimulates patients to recall events and encourages open discussion. A history of sudden infant death syndrome ('cot death'), drowning, or congenital sensorineural deafness may be compatible with long QT syndrome; heart failure and/or cardiac transplantation in a relative are more suggestive of a primary myocardial disorder. Cardiac symptoms in a family member may also be relevant; many patients will recollect parents or siblings suffering recurrent palpitation or blackouts. Subsequent pedigree analysis may indicate which side of the family is affected and in need of targeted evaluation.

\section{The 12-Lead ECG}

The ECG is a relatively sensitive screening investigation for HCM, with the majority of patients demonstrating left axis deviation, repolarisation abnormalities in the left ventricular leads, pathological Q waves, and/or bundle branch block. Voltage criteria for left ventricular hypertrophy are not suggestive of HCM when occurring in isolation, and in the young patient seldom represent significant pathology.

When evaluating patients for inherited cardiovascular disease, the single most important finding in a resting ECG is abnormal repolarisation, which is almost always a sign of underlying cardiac disease. The juvenile pattern of T-wave inversion in V1-V3 should not persist beyond childhood. In the adult, right precordial $\mathrm{T}$-wave inversion is strongly suggestive of ARVC, but may also occur in long QT syndrome. Inverted T waves in V4-V6 are observed in HCM, DCM, left-sided ARVC, and long QT syndrome. Although prolongation of the corrected QT interval is the pathognomonic feature of long QT syndrome, abnormalities in T-wave morphology are common, readily discernible and at times more sensitive. Genotypespecific ST-T patterns have been recognised in different long QT subtypes [39, 40]. Short QT syndrome is characterized by a QT interval of $<320 \mathrm{~ms}$ and tall, narrow $\mathrm{T}$ waves [41-43].

Right precordial ST-segment elevation is the electrocardiographic signature of Brugada syndrome, although also compatible with ARVC [44, 45]. Distinguishing between ARVC and Brugada syndrome in the latter context may be problematic and largely dependent on imaging. Provocative testing with a sodium challenge blocker has been recommended; however, false positives have been documented in the ARVC population [46]. 


\section{The Signal-Averaged ECG}

A 'positive' signal-averaged ECG is a non-specific finding that may occur in coronary artery disease, primary myocardial disorders, and the Brugada syndrome [47]. In ARVC, however, late potentials represent a minor criterion for the disease and as such may enable confirmation of the diagnosis according to task force guidelines when combined with other abnormalities [48].

\section{The $2 D$ Echocardiogram}

The 2D echocardiogram is the first-line screening investigation for structural heart disease, but dependent upon an expert operator. The baseline echocardiogram should include systematic assessment of the following features: global systolic and diastolic function; internal dimensions, wall thickness, and wall motion abnormalities of all four cardiac chambers; valve structure and function, and attempted visualization of the ostia and proximal segments of both coronary arteries. Zeppilli et al. [49] reported satisfactory imaging of the origin of the coronary arteries in $90 \%$ of athletes (mean age: $30 \pm 12$ years) in a 3,500 case series.

A normal ECG and echocardiogram effectively exclude contemporaneous clinical expression of HCM and DCM, but not ARVC. Structural and functional assessment of the right ventricle by echocardiography may be improved by the use of tissue Doppler and administration of intravenous contrast to enhance endocardial border definition. Nevertheless, complementary use of cardiac magnetic resonance is advised in families with features arousing suspicion of ARVC.

\section{The Exercise Test}

Maximal exercise testing is an integral component of the cardiac evaluation, primarily to unmask arrhythmia in ARVC, familial catecholaminergic polymorphic ventricular tachycardia, and long QT syndrome. Frequent ventricular extrasystoles during exercise are a sensitive indicator of underlying cardiac disease and should not be presumed normal in a young person. Long QT syndrome may be associated with failure of the QT interval to shorten normally with increasing heart rates in some patients, and persistent shortening during recovery in others [50, 51]. However, QT adaptability during exercise is exceptionally difficult to interpret without extensive experience in the area.

Exercise testing is of limited value in the diagnosis of $\mathrm{HCM}$, but has an important role in risk stratification. Failure of the systolic blood pressure to rise by $\geq 20 \mathrm{~mm}$ $\mathrm{Hg}$ is one of the risk factors for SCD in HCM. Marked
ST segment depression during exercise is suggestive of ischaemia, often ascribed in HCM patients to capillarymass mismatch and small vessel disease.

Unfortunately, both the baseline and exercise ECG show relatively poor sensitivity in detecting silent coronary artery disease, whether obstructive or anomalous. Among young, asymptomatic adults, a larger absolute number of coronary events will occur among those with an unremarkable exercise test than those with abnormal ST segment changes. This discrepancy is explained by the observation that many acute coronary events result from sudden occlusion of a previously unobstructed segment of the artery, while ST depression on exercise detects ischaemia from pre-existing stenosis [52]. The phenomenon of thrombosis in angiographically normal coronary arteries may be related to activation of a small, non-stenotic atherosclerotic plaque and appears more common among smokers [53, 54].

\section{Ambulatory ECG Monitoring}

24- or 48-hour ambulatory ECG monitoring is of value in documenting spontaneous tachy- and bradyarrhythmia and conduction abnormalities, QT analysis, and quantification of extrasystoles. Low-level ectopic activity may be abnormal in young people; a threshold of 200 ventricular extrasystoles has been proposed as a marker of disease expression in familial ARVC [20]. Couplets and runs of bigeminy on Holter or exercise testing may also be noteworthy.

\section{Supplementary Investigations}

The following additional investigations may be appropriate under specific circumstances.

\section{Cardiovascular Magnetic Resonance (CMR)}

CMR assessment is recommended in any patient or family with one or more features suggestive of ARVC on preliminary evaluation. The validity of CMR in the diagnosis of ARVC is contingent upon expert image acquisition and interpretation. Since high-resolution CMR sequences are dependent on ECG gating, stabilisation of the rhythm prior to scanning is essential for an optimal study. CMR is also indicated in patients in whom anomalous coronary arteries are suspected but could not be excluded on transthoracic echocardiography; CT scanning is an alternative employed at some centres. 


\section{Challenge with a Sodium Channel Blocker}

The signature ECG pattern of Brugada syndrome is dynamic and often concealed, but may be unmasked by provocative challenge with sodium channel blockers such as flecainide, ajmaline, and procainamide. Continuous cardiac monitoring is advised owing to the pro-arrhythmic effects of these drugs. Ajmaline is preferred, if available, as it is inactivated within a few minutes; the half-life of flecainide is $20 \mathrm{~h}$, while the sensitivity of procainamide in the diagnosis of Brugada syndrome has been disputed $[44,55]$. The protocol for drug administration and interpretation of ECG changes is described in the recent consensus report on Brugada syndrome [44]. The ajmaline test is recommended in the following cases, in the absence of discernible structural heart disease: (1) the relatives of an index case with a clinical diagnosis of Brugada syndrome; (2) patients with ECG features suggestive of Brugada syndrome; (3) the patient with unexplained syncope, and (4) the relatives of SADS victims, particularly if the index case suffered SCD in sleep.

\section{Adenosine Challenge for Pre-Excitation}

Intravenous adenosine may unmask latent pre-excitation by blocking the AV node, thereby promoting conduction down an accessory pathway. This test is of use in the familial assessment of Wolff-Parkinson-White syndrome and patients with a history of supraventricular tachycardia, but a normal baseline ECG. Sensitivity and specificity have been cited as 100\% among patients in whom adenosine produces $\mathrm{AV}$ nodal conduction delay or block. The remainder may require invasive electrophysiological studies to exclude latent pre-excitation [56].

\section{Special Considerations in the Athlete}

Cardiovascular adaptations to physical training in elite athletes include increases in cavity dimensions of the left, right, or both ventricles, and mild left ventricular hypertrophy. In a series of 900 elite athletes, around 2\% had a left ventricular wall thickness of $13-15 \mathrm{~mm}$ on echocardiography [57]. Distinguishing between HCM and athletic hypertrophy is facilitated by assessment of several key features. First, left ventricular hypertrophy in HCM occurs at the expense of the left ventricular cavity, but in the athlete is usually associated with increased cavity dimensions to allow beneficial augmentation of stroke volume and cardiac output. Second, impaired diastolic function is observed in HCM, but not a feature of the athlete's heart. A maximum wall thickness $\geq 16 \mathrm{~mm}$ is highly suggestive of HCM. Finally, the ECG is often the most valuable means of differentiation, with pathological Q waves, repolarisation abnormalities, and/or left bundle branch block strongly supporting a diagnosis of HCM [58].

In evaluating the athlete, two important findings always warrant further investigation and should not be attributed to physiological adaptation. The first is the presence of repolarisation abnormalities on a 12-lead ECG, particularly inverted $\mathrm{T}$ waves in the precordial leads (V2V6). The second is the presence of frequent ventricular extrasystoles and/or non-sustained ventricular tachycardia on resting, exercise, or ambulatory ECG. Previous studies have suggested that athletes with these features often have normal echocardiograms and good long-term prognosis $[59,60]$. This does not, however, exclude underlying cardiac disease, notably the concealed phase of ARVC and the inherited arrhythmia syndromes. Serial evaluation is therefore imperative in these cases. Familial assessment is also recommended, and may yield a diagnosis if relatives show features of inherited cardiovascular disease.

\section{Molecular Genetic Analysis}

The past decade has seen elucidation of the genetic basis of the primary myocardial diseases and inherited arrhythmia syndromes (table 1) [15, 16, 42, 43, 61-65]. The absence of a mutation in one of the known diseasecausing genes does not exclude the disease, since many genes have still to be identified. However, isolation of a causative mutation in an affected individual allows cascade screening of families.

One of the main issues arising from clinical application of molecular genetics is the differentiation of a benign polymorphism from a disease-causing mutation. While frameshift mutations are often pathogenic, determining the significance of a missense mutation may require extensive genotype-phenotype correlation. This is facilitated, in the families of SCD victims, by verifying the presence of the mutation in the index case. With the consent of the family, tissue samples retained from the post-mortem may be used for DNA extraction. Since this is an arduous process and yields may be low, systematic genetic analysis of DNA from the proband is seldom practical. However, screening for a specific mutation may be feasible. 


\section{Conclusion}

With improving risk stratification algorithms and the availability of effective therapies, the prevention of SCD is becoming a reality. Timely diagnosis of occult cardiac disease is often the missing link in the chain. Since screening of the general population is not a tenable proposition, targeted evaluation of high-risk subgroups is recommended: individuals with cardiac symptoms, competitive athletes, and the families of SCD victims. The recommend- ed preliminary work-up includes a 12-lead ECG, signalaveraged ECG, transthoracic echocardiogram, exercise test, and ambulatory ECG monitoring. Cardiovascular magnetic resonance has a role in the assessment of ARVC and anomalous coronary arteries, while provocative testing with a sodium channel blocker is of value in unmasking the ECG changes of Brugada syndrome. Single-gene disorders predominate as causes of SCD in the young and molecular genetic analysis may facilitate familial assessment.

\section{References}

$\checkmark 1$ Priori SG, Aliot E, Blomstrom-Lundqvist C, Bossaert L, Breithardt G, Brugada P, Camm AJ, Cappato R, Cobbe SM, Di Mario C, Maron BJ, McKenna WJ, Pedersen AK, Ravens U, Schwartz PJ, Trusz-Gluza M, Vardas P, Wellens HJ, Zipes DP: Task Force on Sudden Cardiac Death of the European Society of Cardiology. Eur Heart J 2001;22:1374-1450.

$\checkmark 2$ Zheng ZJ, Croft JB, Giles WH, Mensah GA Sudden cardiac death in the United States, 1989 to 1998. Circulation 2001;104:21582163.

-3 Straus SM, Bleumink GS, Dieleman JP, van der Lei J, Stricker BH, Sturkenboom MC: The incidence of sudden cardiac death in the general population. J Clin Epidemiol 2004;57:98102.

4 Fox CS, Evans JC, Larson MG, Kannel WB, Levy D: Temporal trends in coronary heart disease mortality and sudden cardiac death from 1950 to 1999: The Framingham Heart Study. Circulation 2004;110:522-527.

$\checkmark 5$ Bowker TJ, Wood DA, Davies MJ, Sheppard MN, Cary NR, Burton JD, Chambers DR, Dawling S, Hobson HL, Pyke SD, Riemersma RA, Thompson SG: Sudden, unexpected cardiac or unexplained death in England: A national survey. QJM 2003;96:269-279.

6 Behr E, Wood DA, Wright M, Syrris P, Sheppard MN, Casey A, Davies MJ, McKenna W: Sudden Arrhythmic Death Syndrome Steering Group: cardiological assessment of first-degree relatives in sudden arrhythmic death syndrome. Lancet 2003;362:1457-1459.

-7 Priori SG, Napolitano C, Schwartz PJ, Grillo M, Bloise R, Ronchetti E, Moncalvo C, Tulipani C, Veia A, Bottelli G, Nastoli J: Association of long QT syndrome loci and cardiac events among patients treated with beta-blockers. JAMA 2004;292:1341-1344.

$\checkmark 8$ McKenna WJ, Oakley CM, Krikler DM, Goodwin JF: Improved survival with amiodarone in patients with hypertrophic cardiomyopathy and ventricular tachycardia. Br Heart J 1985;53:412-416.

$>9$ Maron BJ: Sudden death in young athletes. Lessons from the Hank Gathers affair. N Engl J Med 1993;329:55-57.
10 Corrado D, Fontaine G, Marcus FI, McKenna WJ, Nava A, Thiene G, Wichter T: Arrhythmogenic right ventricular dysplasia/cardiomyopathy: need for an international registry. European Society of Cardiology and the Scientific Council on Cardiomyopathies of the World Heart Federation. J Cardiovasc Electrophysiol 2000;11:827-832.

11 Sen-Chowdhry S, Lowe MD, Sporton SC, McKenna WJ: Arrhythmogenic right ventricular cardiomyopathy: clinical presentation, diagnosis, and management. Am J Med 2004; 117:685-695.

12 Priori SG: Inherited arrhythmogenic diseases: the complexity beyond monogenic disorders. Circ Res 2004;94:140-145.

13 Corrado D, Basso C, Schiavon M, Thiene G Screening for hypertrophic cardiomyopathy in young athletes. N Engl J Med 1998;339:364369.

14 Niimura H, Bachinski LL, Sangwatanaroj S, Watkins H, Chudley AE, McKenna W, Kristinsson A, Roberts R, Sole M, Maron BJ, Seidman JG, Seidman CE: Mutations in the gene for cardiac myosin-binding protein $\mathrm{C}$ and lateonset familial hypertrophic cardiomyopathy. N Engl J Med 1998;338:1248-1257.

>15 Maron BJ, McKenna WJ, Danielson GK, Kappenberger LJ, Kuhn HJ, Seidman CE, Shah PM, Spencer WH 3rd, Spirito P, Ten Cate FJ, Wigle ED American College of Cardiology Foundation Task Force on Clinical Expert Consensus Documents; European Society of Cardiology Committee for Practice Guidelines: American College of Cardiology/European Society of Cardiology Clinical Expert Consensus Document on Hypertrophic Cardiomyopathy: A report of the American College of Cardiology Foundation Task Force on Clinical Expert Consensus Documents and the European Society of Cardiology Committee for Practice Guidelines. Eur Heart J 2003;24: 1965-1991.

16 Crispell KA, Hanson EL, Coates K, Toy W, Hershberger RE: Periodic rescreening is indicated for family members at risk of developing familial dilated cardiomyopathy. J Am Coll Cardiol 2002;39:1503-1507.
17 Jaoude SA, Leclercq JF, Coumel P: Progressive ECG changes in arrhythmogenic right ventricular disease. Evidence for an evolving disease. Eur Heart J 1996; 17:1717-1722.

18 Basso C, Maron BJ, Corrado D, Thiene G: Clinical profile of congenital coronary artery anomalies with origin from the wrong aortic sinus leading to sudden death in young competitive athletes. J Am Coll Cardiol 2000;35: 1493-1501.

19 Nava A, Bauce B, Basso C, Muriago M, Rampazzo A, Villanova C, Daliento L, Buja G, Corrado D, Danieli GA, Thiene G: Clinical profile and long-term follow-up of 37 families with arrhythmogenic right ventricular cardiomyopathy. J Am Coll Cardiol 2000;36:2226-2233.

20 Hamid MS, Norman M, Quraishi A, Firoozi S, Thaman R, Gimeno JR, Sachdev B, Rowland E, Elliott PM, McKenna WJ: Prospective evaluation of relatives for familial arrhythmogenic right ventricular cardiomyopathy/dysplasia reveals a need to broaden diagnostic criteria. J Am Coll Cardiol 2002;40:1445-1450.

21 Neglia D, Michelassi C, Trivieri MG, Sambuceti G, Giorgetti A, Pratali L, Gallopin M, Salvadori P, Sorace O, Carpeggiani C, Poddighe R, L'Abbate A, Parodi O: Prognostic role of myocardial blood flow impairment in idiopathic left ventricular dysfunction. Circulation 2002; 105:186-193.

22 Fontaine G, Fontaliran F, Frank R: Arrhythmogenic right ventricular cardiomyopathies: clinical forms and main differential diagnoses. Circulation 1998;97:1532-1535.

23 Olshansky B: Is syncope the same thing as sudden death except that you wake up? J Cardiovasc Electrophysiol 1997;8:1098-1101.

24 García-Civera R, Ruiz-Granell R, MorellCabedo S, Sanjuan-Mañez R, Ferrero A, Martínez-Brotons A, Roselló A, Botella S, Llacer A: Significance of tilt table testing in patients with suspected arrhythmic syncope and negative electrophysiologic study. J Cardiovasc Electrophysiol 2005; 16:938-942. 
-25 Krahn AD, Klein GJ, Yee R, Hoch JS, Skanes AC: Cost implications of testing strategy in patients with syncope: Randomized assessment of syncope trial. J Am Coll Cardiol 2003;42: 495-501.

-26 Krahn AD, Klein GJ, Skanes AC, Yee R: Use of the implantable loop recorder in evaluation of patients with unexplained syncope. J Cardiovasc Electrophysiol 2003;14(9 suppl):S70_ S73.

-27 Basso C, Thiene G, Corrado D, Angelini A, Nava A, Valente M: Arrhythmogenic right ventricular cardiomyopathy. Dysplasia, dystrophy, or myocarditis? Circulation 1996;94: 983-991.

-28 Bauce B, Basso C, Rampazzo A, Beffagna G, Daliento L, Frigo G, Malacrida S, Settimo L, Danieli GA, Thiene G, Nava A: Clinical profile of four families with arrhythmogenic right ventricular cardiomyopathy caused by dominant desmoplakin mutations. Eur Heart J 2005;26: 1666-1675.

-29 Sen-Chowdhry S, Syrris P, McKenna WJ: Desmoplakin disease in arrhythmogenic right ventricular cardiomyopathy: early genotype-phenotype studies. Eur Heart J 2005;26:15821584.

-30 Alawadhi M, Thanassoulis G, Marcil M, Genest J: Genetic lipoprotein disorders and coronary atherosclerosis. Curr Atheroscler Rep 2005; 7:196-203.

>31 Weber M, McNicoll S, Marcil M, Connelly P, Lussier-Cacan S, Davignon J, Latour Y, Genest J Jr: Metabolic factors clustering, lipoprotein cholesterol, apolipoprotein B, lipoprotein (a) and apolipoprotein E phenotypes in premature coronary artery disease in French Canadians. Can J Cardiol 1997; 13:253-260.

>32 Pay S, Ozcan N, Tokgozoglu SL: Elevated $\mathrm{Lp}(\mathrm{a})$ is the most frequent familial lipoprotein disorder leading to premature myocardial infarction in a country with low cholesterol levels. Int J Cardiol 1997;60:301-305.

\33 Pac FA, Ozerol E, Ozerol IH, Temel I, Ege E, Yologlu S, Sezgin N, Sahin K, Emmiler M, Pac M, Aslan H: Homocysteine, lipid profile, nitric oxide, vitamin B12, and folate values in patients with premature coronary artery disease and their children. Angiology 2005;56:253257.

-34 Nguyen HH, Wolfe JT 3rd, Holmes DR Jr, Edwards WD: Pathology of the cardiac conduction system in myotonic dystrophy: a study of 12 cases. J Am Coll Cardiol 1988;11:662671.

-35 Rakocevic-Stojanovic V, Pavlovic S, Seferovic P, Vasiljevic J, Lavrnic D, Marinkovic Z, Apostolski S: Pathohistological changes in endomyocardial biopsy specimens in patients with myotonic dystrophy. Panminerva Med 1999;41:27-30.
36 Schwartz PJ, Priori SG, Spazzolini C, Moss AJ, Vincent GM, Napolitano C, Denjoy I, Guicheney P, Breithardt G, Keating MT, Towbin JA, Beggs AH, Brink P, Wilde AA, Toivonen L, Zareba W, Robinson JL, Timothy KW, Corfield V, Wattanasirichaigoon D, Corbett C, Haverkamp W, Schulze-Bahr E, Lehmann MH, Schwartz K, Coumel P, Bloise R: Genotype-phenotype correlation in the longQT syndrome: gene-specific triggers for lifethreatening arrhythmias. Circulation 2001; 103:89-95.

37 Maron BJ, Roberts WC, Epstein SE: Sudden death in hypertrophic cardiomyopathy: a profile of 78 patients. Circulation 1982;65:13881394.

38 Tabib A, Loire R, Chalabreysse L, Meyronnet D, Miras A, Malicier D, Thivolet F, Chevalier P, Bouvagnet P: Circumstances of death and gross and microscopic observations in a series of 200 cases of sudden death associated with arrhythmogenic right ventricular cardiomyopathy and/or dysplasia. Circulation 2003;108: 3000-3005.

39 Zhang L, Timothy KW, Vincent GM, Lehmann MH, Fox J, Giuli LC, Shen J, Splawski I, Priori SG, Compton SJ, Yanowitz F, Benhorin J, Moss AJ, Schwartz PJ, Robinson JL, Wang Q, Zareba W, Keating MT, Towbin JA, Napolitano C, Medina A: Spectrum of ST-Twave patterns and repolarization parameters in congenital long-QT syndrome: ECG findings identify genotypes. Circulation 2000;102: 2849-2855.

40 Moss AJ: T-wave patterns associated with the hereditary long QT syndrome. Card Electrophysiol Rev 2002;6:311-315.

41 Gaita F, Giustetto C, Bianchi F, Wolpert C, Schimpf R, Riccardi R, Grossi S, Richiardi E, Borggrefe M: Short QT syndrome: a familial cause of sudden death. Circulation 2003;108: 965-970.

42 Brugada R, Hong K, Dumaine R, Cordeiro J, Gaita F, Borggrefe M, Menendez TM, Brugada J, Pollevick GD, Wolpert C, Burashnikov E, Matsuo K, Wu YS, Guerchicoff A, Bianchi F, Giustetto C, Schimpf R, Brugada P, Antzelevitch C: Sudden death associated with short-QT syndrome linked to mutations in HERG. Circulation 2004;109:30-35.

43 Schimpf R, Wolpert C, Gaita F, Giustetto C Borggrefe M: Short QT syndrome (review). Cardiovasc Res 2005;67:357-366.

44 Antzelevitch C, Brugada P, Borggrefe M, Brugada J, Brugada R, Corrado D, Gussak I, LeMarec H, Nademanee K, Perez Riera AR, Shimizu W, Schulze-Bahr E, Tan H, Wilde A: Brugada syndrome: report of the second consensus conference: endorsed by the Heart Rhythm Society and the European Heart Rhythm Association. Circulation 2005;111: 659-670

45 Corrado D, Basso C, Buja G, Nava A, Rossi L, Thiene G: Right bundle branch block, right precordial ST-segment elevation, and sudden death in young people. Circulation 2001;103: 710-717.
46 Peters S, Trummel M, Denecke S, Koehler B: Results of ajmaline testing in patients with arrhythmogenic right ventricular dysplasiacardiomyopathy. Int J Cardiol 2004;95:207210.

47 Antzelevitch C: Late potentials and the Brugada syndrome. J Am Coll Cardiol 2002;39: 1996-1999.

48 McKenna WJ, Thiene G, Nava A, Fontaliran F, Blomstrom-Lundqvist C, Fontaine G, Camerini F: Diagnosis of arrhythmogenic right ventricular dysplasia/cardiomyopathy. Task Force of the Working Group Myocardial and Pericardial Disease of the European Society of Cardiology and of the Scientific Council on Cardiomyopathies of the International Society and Federation of Cardiology. Br Heart J 1994;71: 215-218.

49 Zeppilli P, dello Russo A, Santini C, Palmieri V, Natale L, Giordano A, Frustaci A: In vivo detection of coronary artery anomalies in asymptomatic athletes by echocardiographic screening. Chest 1998;114:89-93.

$\checkmark 50$ Krahn AD, Klein GJ, Yee R: Hysteresis of the RT interval with exercise: a new marker for the long-QT syndrome? Circulation 1997;96: 1551-1556.

51 Vincent GM, Jaiswal D, Timothy KW: Effects of exercise on heart rate, QT, QTc and QT/QS2 in the Romano-Ward inherited long QT syndrome. Am J Cardiol 1991;68:498-503.

52 Fowler-Brown A, Pignone M, Pletcher M, Tice JA, Sutton SF, Lohr KN; U.S. Preventive Services Task Force: Exercise tolerance testing to screen for coronary heart disease: a systematic review for the technical support for the U.S. Preventive Services Task Force. Ann Intern Med 2004;140:W9-W24.

53 Gehani AA, al-Mulla AW, Chaikhouni A, Ammar AS, Mahrous F, Tirkawi R, Ashraf A, Hajar HA: Myocardial infarction with normal coronary angiography compared with severe coronary artery disease without myocardial infarction: the crucial role of smoking. J Cardiovasc Risk 2001;8:1-8.

54 McKenna WJ, Chew CY, Oakley CM: Myocardial infarction with normal coronary angiogram. Possible mechanism of smoking risk in coronary artery disease. Br Heart J 1980;43: 493-498.

55 Wilde AA, Antzelevitch C, Borggrefe M, Brugada $\mathrm{J}$, Brugada $\mathrm{R}$, Brugada $\mathrm{P}$, Corrado $\mathrm{D}$, Hauer RN, Kass RS, Nademanee K, Priori SG, Towbin JA; Study Group on the Molecular Basis of Arrhythmias of the European Society of Cardiology: Proposed diagnostic criteria for the Brugada syndrome. Eur Heart J 2002;23: 1648-1654.

56 Garratt CJ, Antoniou A, Griffith MJ, Ward DE, Camm AJ: Use of intravenous adenosine in sinus rhythm as a diagnostic test for latent preexcitation. Am J Cardiol 1990;65:868873 
$\checkmark 57$ Pelliccia A, Maron BJ, Spataro A, Proschan MA, Spirito P: The upper limit of physiologic cardiac hypertrophy in highly trained elite athletes. N Engl J Med 1991;324:295-301.

>58 Firoozi S, Sharma S, Hamid MS, McKenna WJ: Sudden death in young athletes: HCM or ARVC? Cardiovasc Drugs Ther 2002;16:1117.

59 Pelliccia A, Maron BJ, Culasso F, Di Paolo FM, Spataro A, Biffi A, Caselli G, Piovano P: Clinical significance of abnormal electrocardiographic patterns in trained athletes. Circulation 2000;102:278-284.
60 Biffi A, Pelliccia A, Verdile L, Fernando F, Spataro A, Caselli S, Santini M, Maron BJ: Long-term clinical significance of frequent and complex ventricular tachyarrhythmias in trained athletes. J Am Coll Cardiol 2002;40: 446-452.

61 Priori SG, Napolitano C, Vicentini A: Inherited arrhythmia syndromes: applying the molecular biology and genetic to the clinical management. J Interv Card Electrophysiol 2003;9: 93-101.

62 Towbin JA, Bowles NE: The failing heart. Nature 2002;415:227-233.

63 Sen-Chowdhry S, Syrris P, McKenna WJ: Genetics of right ventricular cardiomyopathy (review). J Cardiovasc Electrophysiol 2005; 16: 927-935.
64 Priori SG, Pandit SV, Rivolta I, Berenfeld O, Ronchetti E, Dhamoon A, Napolitano C, Anumonwo J, di Barletta MR, Gudapakkam S, Bosi G, Stramba-Badiale M, Jalife J: A novel form of short QT syndrome (SQT3) is caused by a mutation in the KCNJ2 gene. Circ Res 2005;96:800-807

65 Bellocq C, van Ginneken AC, Bezzina CR, Alders M, Escande D, Mannens MM, Baro I, Wilde AA: Mutation in the KCNQ1 gene leading to the short QT-interval syndrome. Circulation 2004; 109:2394-2397. 